\title{
Assessing the Effectiveness of Urban Nature Reserves on Biodiversity Conservation
}

\author{
Mukete Beckline, Sun Yujun* \\ Laboratory for Silviculture and Conservation, Beijing Forestry University, Beijing, China \\ *Corresponding author: sunyj@bjfu.edu.cn
}

Received October 09, 2014; Revised October 25, 2014; Accepted December 10, 2014

\begin{abstract}
Around the globe, environmental policies have always favouredurban green spaces for recreation and tourism. But, these green spaces also serve as habitats for plant and animal species, facilitate soil water retention and carbon sequestration. One of such green spaces, is the Byoasen located in the Nørrebro suburb of Copenhagen, Denmark. A biodiversity survey was conducted aimed at assessing species composition, richness and biological heterogeneity. The species richness (flora and fauna) data were collected and weighted against natural factors e.g. arbor cover and anthropogenic factors e.g. human activity. The results suggested that biodiversity richness increased with increased arbor cover and within areas with little human access.
\end{abstract}

Keywords: Biodiversity, fauna, flora, green space, Byoasen, habitat, species

Cite This Article: Mukete Beckline, and Sun Yujun, “Assessing the Effectiveness of Urban Nature Reserves on Biodiversity Conservation.” Applied Ecology and Environmental Sciences, vol. 2, no. 6 (2014): 130-134. doi: 10.12691/aees-2-6-1.

\section{Introduction}

In Denmark as in other countries around the globe, governmental policies strongly favour green spaces around human habitats [1]. About 14\% of Danish territory is under some form of protection since the first Nature Conservation Act of 1917. The country boasts over 100 nature reserves covering a total surface of about 330,000 hectares [1]. These protected areas are meant to foster visitor appreciation and understanding on a broad spectrum of ecologically, environmentally, economically and socially sustainable nature-based management activities [2-6].

Facilitated by biogeophysical microclimatic processes (e.g. arbor coverage) that influence surface albedo, rate of evapotranspiration, temperature and precipitation, green spaces also enhance and conserve biodiversity[7,8,9]. Therefore, green spaces possess conservation profiles as natural ecosystems that enhance species survival, have habitat heterogeneity and biodiversity richness [10-14]. Green spaces are also known to provide habitat for a variety of birds, fish, mammals and insects as well as corridors or greenways to link fragmented habitats $[15,16,17]$.

Biodiversity is the integration of the variety and variation of all living organisms as related to their habitats and ecological complexes $[7,9,18]$. With its three primary attributes composition, structure and process, biodiversity is organized into a nested hierarchy from genes to species, populations and ecosystems. It is hence the basic biotic resource necessary to sustain the human life-support system and fulfil anthropocentric exigencies [19,20].
Humans comprise about $1 \%$ of earth's total living biomass yet their impact via urbanization and agriculture are major pushers of biodiversity loss [3,21,22,23]. This biodiversity loss disrupts ecosystems leading to vulnerability, less resilience and a failure to supply humans with needed services [11,17,24,25].

Based on the recognition that green areas are important for biodiversity conservation and recreation, this study assesses the importance of the Byoasen green area to biodiversity conservation in Denmark.

\section{Methodology}

\subsection{Study Area}

This study was conducted between October and December 2011 at the Byoasen green area Nørrebro,

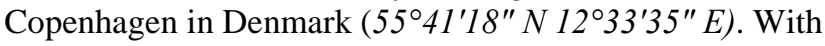
an area of $3.82 \mathrm{~km}^{2}$ and about 72000 residents, Nørrebro is Copenhagen's most densely populated neighbourhood [26]. The green space covers an area of over 3.0 hectares with lawns, trees, fruit gardens, fish pond, animal farm and a greenhouse.

\subsection{Biodiversity Survey}

A survey according to [27], was used to obtain data on species composition, richness and taxa heterogeneity (Table 1). To avoid inconsistencies, baseline data was established to monitor and it was designed based on ecological functional groups as described by [28,29]. Using a Keson field measuring tape(Model NRS100M made by Keson Industries USA Inc), the sample area was divided into four separate zones of 0.75 hectares $\left(75 \mathrm{~m}^{2}\right)$. 
The tape was further used to measure and demarcate each zone into 10 different plots of $7.5 \mathrm{~m}^{2}$ i.e. 10 plots per zone and 40 plots in all. Each of the four zones and its constituent 10 plots, was then assessed by direct identification and observation with the naked eye. To avoid inaccurate data, each zone was assessed twice usually on a different day and time.

Species richness was divided into six categories including lower and higher plants, birds, mammals, all worms categorized as nematodes and arthropods as insects (Table 1).

A sum total of different plant and animal species observed was recorded and the estimated average is presented in Table 2. Furthermore, using the sum total of all observations, a general comparison between the different zones was performed. Here, species richness at the taxa level was weighted against natural and anthropogenic factors and the data analyzed using Microsoft Excel Software (Figure 1 - Figure 4). A correlation analysis using Microsoft Excel Software was also performed to check for interrelationships in the biodiversity data obtained (Figure 5 - Figure 9).

Table 1. Estimated parameters

\begin{tabular}{|c|c|}
\hline Flora & Fauna \\
\hline Lower plants & Nematodes \\
\hline Higher plants & Insects \\
\hline & Birds \\
\hline & Mammals \\
\hline
\end{tabular}

Table 2. Observed average biodiversity distribution data per zone

\begin{tabular}{|c|c|c|c|c|}
\hline Parameter & Zone A & Zone B & Zone C & Zone D \\
\hline Higher plants & 6.2 & 13.4 & 9.4 & 6 \\
\hline Lower plants & 0.2 & 1.4 & 1 & 0.4 \\
\hline Insects & 7 & 8 & 6 & 2 \\
\hline Birds & 2 & 3.2 & 2.3 & 1 \\
\hline Worms & 2 & 2.2 & 2 & 1.3 \\
\hline Mammals & 0.2 & 1.3 & 0 & 0.2 \\
\hline
\end{tabular}

\section{Results}

\subsection{Observed Biodiversity Richness Data per Plot in all Four Zones}

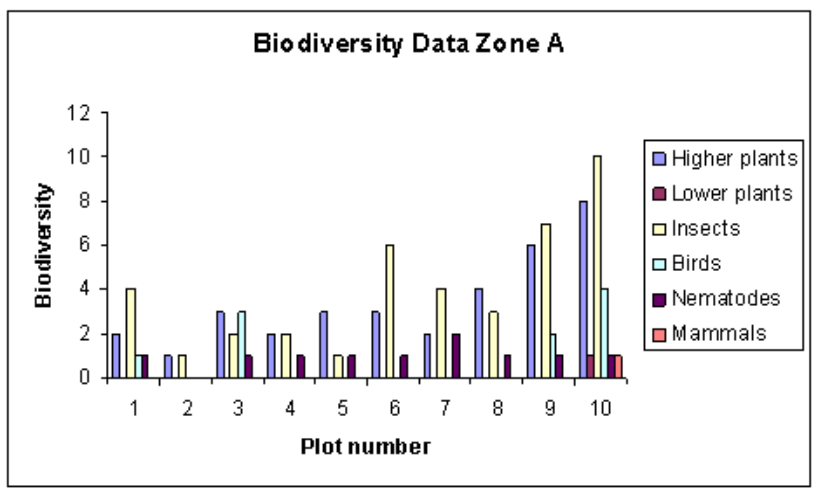

Figure 1. Biodiversity data zone A

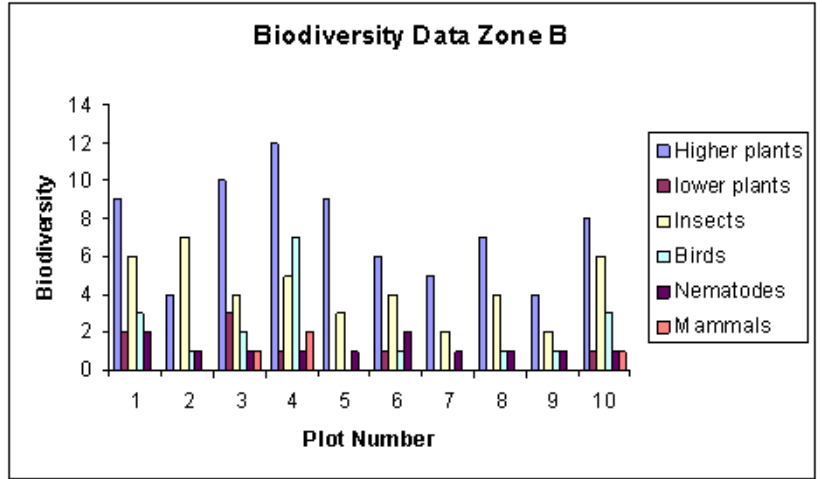

Figure 2. Biodiversity data zone B

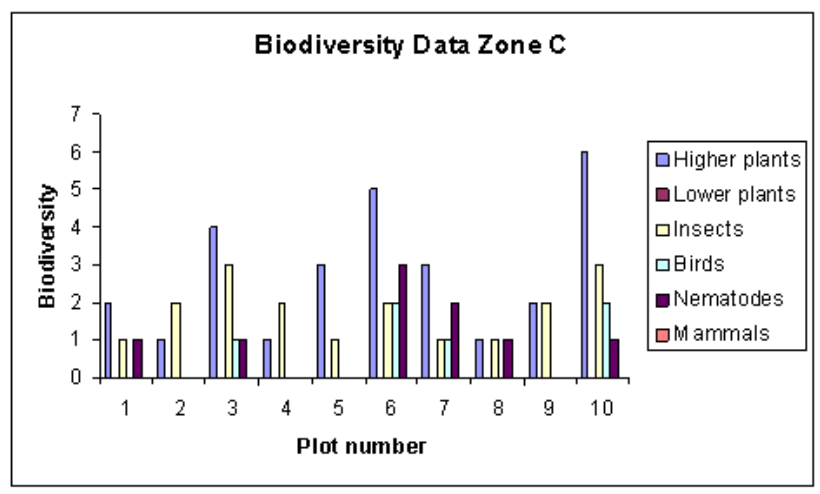

Figure 3. Biodiversity data zone C

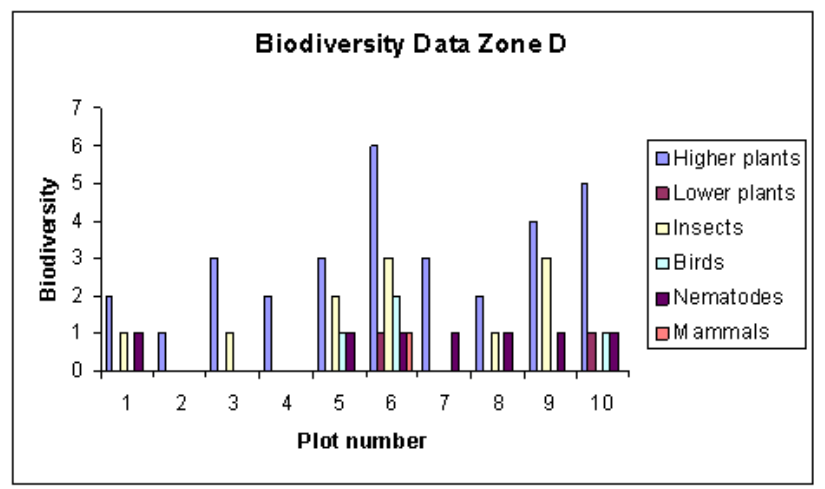

Figure 4. Biodiversity data zone D

\subsection{Correlation Analysis}

\section{Correlation Zone B}

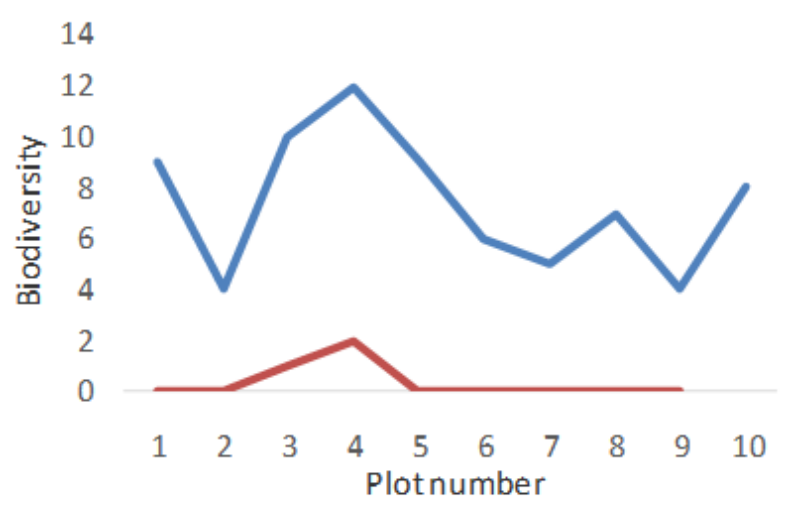

- Higher plants Mammals

Figure 5. Correlation Zone B 
Correlation Zone A

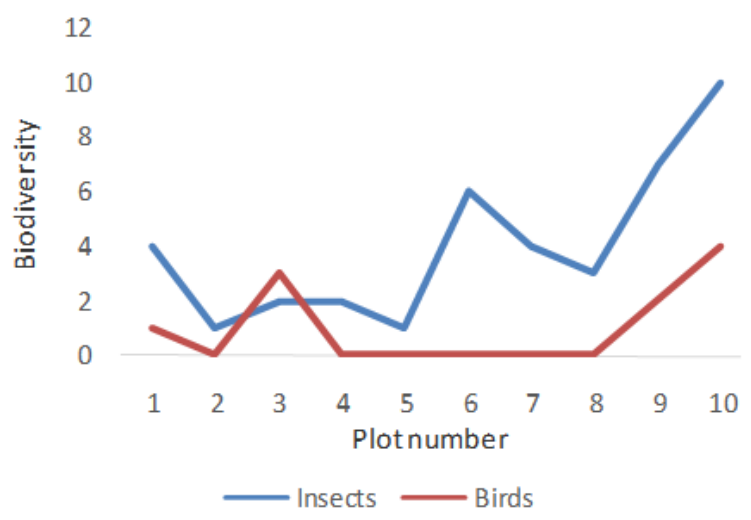

Figure 6. Correlation Zone A

Correlation Zone C

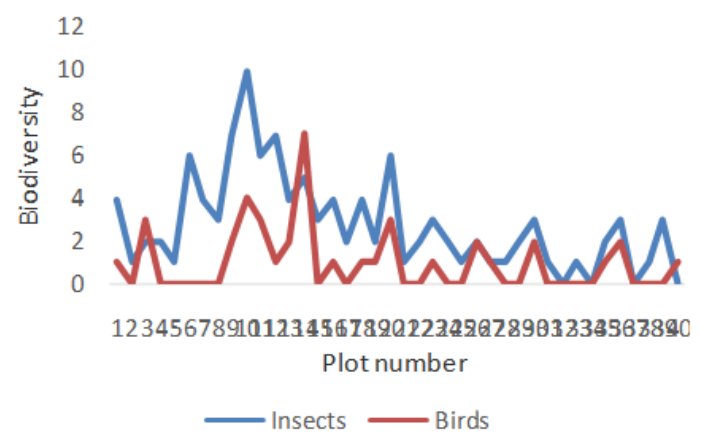

Figure 7. Correlation Zone C

\section{Correlation Zone D}
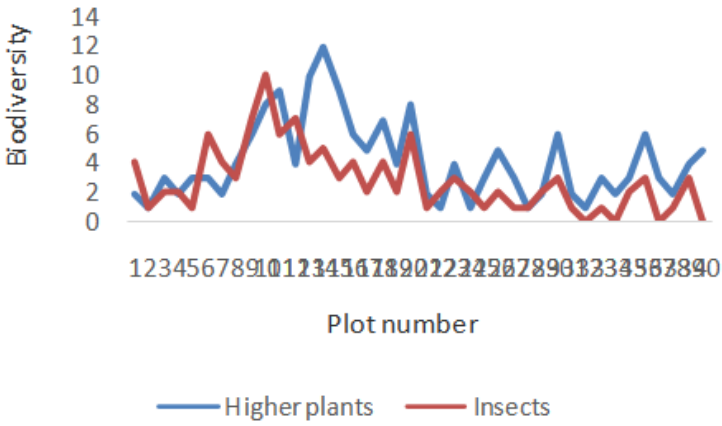

Figure 8. Correlation Zone D

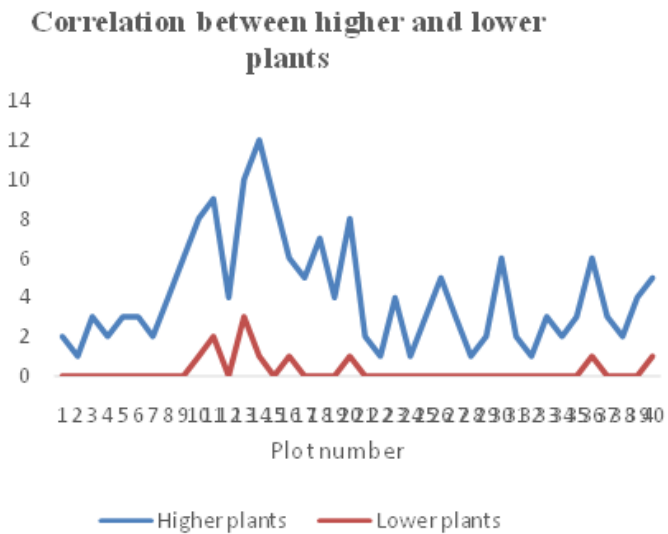

Figure 9. Correlation between Higher and Lower plants
It was observed that, biodiversity richness was mostly as higher plants and insects with few birds in zones B and $\mathrm{C}$ but was much less in zones A and D. Like the worms, mammals were absent in zone $\mathrm{C}$ and a few observed in zones $\mathrm{A}$ and $\mathrm{B}$. The worm species was sparse with the earthworm, Dendrobaenaoctaedra and parasitic nematode of potatoes and tomato plants, Globoderarostochiensis the most common. These worms were found in zones B and C that included areas adjacent and surrounding the fruit and vegetable gardens. Also, lower plants exhibited little presence except for a few ferns, algae and mosses such as the Anthocerotopsida species. This study found out that zones $\mathrm{B}$ and $\mathrm{C}$ were richer in birds and insects species than zones $\mathrm{A}$ and D. Furthermore, the correlation analyses showed a direct relationship between lower plants and higher plants, higher plants and insects, insects and birds as well as between higher plants and mammals. A caution in interpreting our results would be that, the data is only of overall species richness (number of species) and not species identity (classification).

\section{Discussion}

The study showed a zonal variation in species richness and for different taxa. For instance, species richness at zones $\mathrm{B}$ and $\mathrm{C}$ were completely different from that of zones A and D. This observation pointed to the fact that, species richness increases with an increase in tree cover such as in green spaces and forested landscapes. Several studies [13,30,31,32,33], have examined species richness for different organisms along a disturbance gradient and have found similar results. But none of these studies including [34], could reveal any single species or groups of species suitable for use as predictors of overall biodiversity richness.

Richness in insect species was higher in zones A, B and $C$ but lower in zone $\mathrm{D}$. This could be attributed to richness in higher plant species within zones A, B and C in contrast to zone D. Moreso, arthropod species colonize areas where they can favorably interact with their environment especially in dense vegetation cover. This is because, thick foliage provides a haven for protection and escape route from predators such as birds and rodents. Also, [16] observed that, large trees had a consistent, strong and positive relationship with five measures of bird diversity. Their study affirmed that, as trees become larger in size, their positive effect on bird diversity increased. Their findings then concluded that, large urban trees are therefore keystone structures that provide crucial habitat resources for wildlife.

Belowground organisms like detritivores, decomposers and saprophytes tend to also colonize these moist environments where, they play many different functional roles necessary for maintaining the ecosystem dynamics $[2,29]$. This observation confirmed the works of $[35,36]$ whose experiments showed a correlation between plant diversity and both aboveground and belowground consumers. Similarly [37] concluded that, insectivores and foliage foraging bird species contributed to increasing overall species number while ground foraging species negatively affected the overall avian diversity of a community. The difference in bird species richness also suggested that, birds use these trees as habitats, to perch 
and hunt for food [38]. Furthermore, bird richness is influenced by the presence of prey or food which suggested that, most of the bird species observed did use the insects as a source of food.

Studying land cover in urban areas $[39,40]$ concluded that, changes in land cover can alter hydrology, soil properties, geomorphology, disturbance regimes and local climates of urban areas which in turn can influence local ecological communities. They also concluded that, conversion and rearrangement of land cover affects colonization species dynamics while extinction determines the richness, evenness (relative dominance) and composition of urban animal communities. Their findings suggested that increased shrub in stand level was effective to increase the overall species number.

Temperature is a major factor that may have caused a drop in biodiversity richness in zone D. This study was carried out in autumn and near winter months when yellowing in tree leaves and drop in arbor cover commenced. This observation tallied with studies by $[41,42]$. Both studies showed that, butterfly diversity and species composition changed predictably in response to changes in vegetative structural diversity and microhabitat characteristics such as temperature and moisture. [15,31] found that because of canopy cover, forest habitats were noticeably cooler and more humid than restored habitats. They therefore affirmed that, microclimatic factors are particularly important in determining species richness [16].

Furthermore, Zone D harbours the greenhouse, the fish pond and all entrances to the retirement homes. This open access nature and intensive human activity during the day and at night negatively drives species richness. This is because human disturbances on biodiversity results from overt or directed activities on biodiversity, manifested by fright, flight, disablement or death. This observation is similar to that of zone A which covered the north gate and crisscrossing paths leading to the animal house. Studies by $[13,43,44]$ also concluded that, human activity plays an important role in driving and determining biodiversity richness within green spaces.

Mammal diversity as observed within the different zones, is influenced by plant cover, fragmentations and absence of corridors. These limit access and inter-forested area movements for mammals or little rodents thus limiting possibilities for colonization by foreign species. Using data from remotely triggered infra-red cameras, [45] found similar results for bobcats and coyotes. They observed that, these mammals displayed a relatively wide range of activity levels at sites with low human use. Whereas, they displayed a lower and markedly restricted range of activity at those sites with the highest levels of recreation. On the other hand, because of their ability to fly, bird and some flying insect species are able to rapidly colonize this area.

\section{Conclusion}

The study showed that, due to biogeophysical microclimatic processes, biodiversity or species richness increases with increase arbor cover and within areas with little human access. It also suggested that apart from fostering visitor appreciation, green spaces also provide habitat for a variety of animal and plant species in a nested hierarchy of habitat heterogeneity.

Despite, the high frequency of human disturbance due to the animal house, retirement home and green house as well as its fragmented nature or lack of corridors, the Byoasen green area plays a major role in biodiversity conservation in Denmark.

\section{Acknowledgment}

This study was supported by the Special Public Interest Research and Industry Fund of Forestry (No.200904003$1)$; and Project of Forestry Science and Technology Research (No. 2012-07); and Forestry Extension Program of Science and Technology (No.[2014] 26).

\section{References}

[1] The Danish Government (2004). Action Plan for Biodiversity and Nature Conservation in Denmark 2004-2009. Retrieved, $12^{\text {th }}$ November, 2014 http://eng.naturstyrelsen.dk/media/nst/Attachments/ActionPlan_30 0604.pdf

[2] Jenkins, C and Joppa, L (2009). Expansion of the global terrestrial protected area system. Biological. Conservation 142, 2166-2174.

[3] Middleton, J (1994). Effects of urbanization on biodiversity in Canada. In: Biodiversity in Canada: A Science Assessment for Environment Canada. Environment Canada, Ottawa, pp. 15-20.

[4] Rohde, C and Kendle, D (1994). Human well-being, natural landscapes and wildlife in urban areas. A review. English Nature Science No. 22.

[5] Valentine, J., Heck, K., Webbs, D and Busby, J (1997). Experimental evidence that herbivory increases shoot density and productivity in subtropical turtle grass (Thalassia Macmahontestudinum) meadow. Oekologia 112: 193-200.

[6] Wells, M and McShane, T (2004). Integrating protected area management with local needs and aspirations. Ambio 33, 513-519.

[7] Savard, L., Clergeau, P and Mennechez, G (2000). Biodiversity concepts and urban ecosystems. Landscape and Urban Planning 48:131-142

[8] Leakey, R and Tentchou, J (2009). Consultant's Report, MidTerm Evaluation, Agricultural and Tree Products Program, Food for Progress 2006, 26 Jan - 13 Feb 2009. Report to World Agroforestry Centre, Yaoundé, Cameroon, 86 pp.

[9] UN-Habitat (2012). Urban Patterns for a Green Economy: Working with Nature. Online at www.unhabitat.org/pmss/listItemDetails.aspx?publicationID=334 1.

[10] Saunders, D., Hobbs, R and Marguler, C (1991). Biological consequences of ecosystem fragmentation: a review. Conservation Biology 5: 18-32.

[11] Dunning, J., Danielson, J and Pulliam, H (1992). Ecological processes that affect populations in complex landscapes. Oikos 65: 159-175.

[12] Wilby, R and Perry, W (2006). Climate change, biodiversity and the urban environment: A critical review based on London, UK. Progress in Physical Geography 30 (1): 73-98.

[13] Nielsen, A; van den Bosch, M; Maruthaveeran, S and van den Bosch, K (2013). Species richness in urban parks and its drivers: A review of empirical evidence. Urban Ecosystems (17) 1 305327.

[14] Coetzee, B; Kevin, J and Steven, L (2014). Local Scale Comparisons of Biodiversity as a Test for Global Protected Area Ecological Performance: A Meta-Analysis. PLoS ONE, 2014; 9 (8): e105824.

[15] Zhou, L., Shi, W., Xue, W., Wang, T., Zhenming, G., Zhou, H and Hui, Z (2005). Relationship between vegetation structure and the temperature and moisture in urban green spaces of Shanghai. Chinese journal of ecology, 24-09-2005.

[16] Karen, S., Lindenmayer, D., Knight E., Fischer, J and Manning, D (2012). Large trees are keystone structures in urban parks. Conservation Letters 5 (2), 115-122. 
[17] Le Roux, D., Ikin, K., Lindenmayer, B., Blanchard, W., Manning, A and Gibbons, P (2014). Reduced availability of habitat structures in urban landscapes: Implications for policy and practice Landscape and Urban Planning 125, Pages 57-64.

[18] Kim, C (1993). Biodiversity, conservation and inventory: why insects matter Biodiversity and Conservation 2, 191-214.

[19] Convention on Biological Diversity-CBD (2006). Sustaining Life on Earth. Global Diversity Outlook. No: UNEP/CBD/COP/8/12.

[20] Lester, B (2008). Out growing the Earth. The food security challenge in an age of falling water tables and rising temperatures. Earth Policy Institute. Revised January 2008.

[21] Zhou, Y and Tol, R (2004). Evaluating the costs of desalination and water transport: Center for Marine and Atmospheric Sciences, Hamburg University and Institute of Environmental SciencesVrije University, Amsterdam. Retrieved February, 2009.

[22] Caspersen, O., Konijnendijk, C and Olafsson, A (2006). Green space planning and land use: An assessment of urban regional and green structure planning in Greater Copenhagen. Danish Journal of Geography 106 (2): 7-20, 2006

[23] Maiorano, L., Falcucci, A.andBoitani, L (2008). Size-dependent resistance of protected areas to land-use change. Proc. R. Soc. B 275, 1297-1304.

[24] United Nations Environmental Program-UNEP (2006). Sustaining Life on Earth, Convention on Biological Diversity 8th meeting Curitiba, Brazil, 20th -31st March, 2006

[25] Laurance et al., (2012). Averting Biodiversity Collapse in Tropical Forest Protected Areas. Nature 489 (7415) 290-94.

[26] København Kommune (2009). Folketal og boliger i bydele og roder samt folketal i skoledistrikter 1. januar 2009. Retrieved 2011-12-01.

[27] Clarke, R (1986). The Handbook of Ecological Monitoring, a GEMS IUNEP publication. Oxford: Clarendon Press.

[28] Noss, F (1990). Indicators for monitoring biodiversity: a hierarchical approach, Conservation Biology 4: 355-64.

[29] Walker, B (1992). Biodiversity and ecological redundancy. Conservation Biology 6: 8-23

[30] Lawton, H., Bignell, E., Bolton, B., Bloemers, F., Eggleton, P., Hammond, P (1998). Biodiversity inventories, indicator taxa and effects of habitat modification in tropical forest. Nature 391: 72-75.

[31] Perfecto, I., Vandermeer, J., Masand, A and Pinto, L (2005). Biodiversity, yield and shade coffee certification. Ecological Economics 54 (4) 435-446.

[32] Knapp, S., Kühn, I., Stolle, J and Klotz, S (2010). Changes in the functional composition of a Central European urban flora over three centuries. Perspectives in Plant Ecology, Evolution and Systematics 12: 235-244.

[33] Vojtěch, J., Petr, P and Tomáš, K (2011). Alien plants in urban nature reserves: from red-list species to future invaders? NeoBiota 10: $27-46$.

[34] Howard, C., Viskanic, P., Devenport, B., Kigenyi, W., Baltzer, M and Dickinson, C. (1998). Complementarity and the use of indicator groups for reserve selection in Uganda. Nature 394:472475.

[35] Siemann, E (1998). Experimental tests of effects of plant productivity and diversity on grassland arthropod diversity. Ecology 79, 2057-2070.

[36] Hartley, M., Rogers, W and Siemann, E (2010). Comparisons of arthropod assemblages on an invasiveand native trees: abundance, diversity and damage. Arthropod-Plant Interactions 4:237-245.

[37] Haruka, I and Nakashizuka, T (2010). Environmental factors affecting the composition and diversity of avian community in mid- to late breeding season in urban parks and green spaces. Landscape and Urban Planning 96, 183-194.

[38] Calvo, L and Blake, J (1998). Bird diversity and abundance on two different shade coffee plantations in Guatemala. Birds Conservation International 8: 297-308.

[39] Marzluff, M., Withey, C., Whittaker, K., Oleyar, D., Unfried, T., Rullman, S., and DeLap, J (2007). Consequences of habitat utilization by nest predators and breeding songbirds across multiple scales in an urbanizing landscape. Condor 109:516-534.

[40] Marzluff, J and Rodewald, A (2008). Conserving Biodiversity in Urbanizing Areas: Nontraditional Views from a Bird's Perspective. Cities and the Environment (1) 2 Article 6, 27 pp.

[41] Estrada, A., Coates-Estrada, S and Merrit, D (1997). Anthropogenic landscape changes and avian diversity at Los Tuxtlas, Mexico. Biodiversity and Conservation 6: 19-43.

[42] Hamer, C., Hill, K., Lace, L and Largon, M (1997). Ecological and biogeographical effects of forest disturbance on tropical butterflies of Sumba, Indonesia. Journal of Biogeography 24: 6775.

[43] Alvey, A (2006).Promoting and preserving biodiversity in the urban forest. Urban Forestry and Urban Greening 5 195-201.

[44] Toth, F., Haight, G., Snyder, A., George, S., Miller, R., Gregory, S and Skibbe, A (2009). Reserve selection with minimum contiguous area restrictions: An application to open space protection planning in suburban Chicago. Biological Conservation 142: 1617-1627.

[45] Shalene, L and Crooks, R (2006). Recreation and large mammal activity in an urban nature reserve. Biological Conservation 133 (1) 107-117. 